\title{
Urban heritage and its role in the development of the tourism sector: a model of two cities - Hebron and Bethlehem, Palestine
}

\author{
G. J. Dweik \\ Palestine Polytechnic University (PPU), Palestine
}

\begin{abstract}
Urban heritage has an important status in the process of developing the Palestinian tourism sector. Urban heritage differs depending on the regions and historical cities such as Jerusalem, Hebron, and Jericho among others. Within this framework, the Palestinian National Authority (PA), based on its new schemes and strategies, seeks to activate an economic, cultural, social, and tourist role in maintaining heritage through preserving and rehabilitating sites and buildings. In addition, PA seeks to find suitable solutions to financial projects, restore, and cherish this valuable historical heritage.

The research aims at highlighting the importance of urban heritage in the cities of Hebron and Bethlehem that abound in historical and tourism elements especially the urban heritage represented in the old city, al-Qasaba, historical walls, and others. Moreover, the research seeks to highlight the most important weaknesses from which this sector suffers.

Finally, this research paper attempts to find successful solutions to maintain and raise the value of heritage and to appreciate its effective role in the tourism sector.
\end{abstract}

Keywords: Hebron, Bethlehem, historical cities, tourism sector, architectural heritage.

\section{Introduction}

Palestinian cities are rich with an urban heritage that plays an important role in developing economic, cultural, and social life. In order to guarantee this important historical credit, it must be integrated within the general fabric of the city and to be placed within a comprehensive urban planning that provides 
techniques and needed guidelines for the revival and preservation of architectural heritage (Figure 1).

Incentives shall be offered to achieve an adequate development of the historical cities. The plan will lead to find viable economic structures to revive the historical cities and to make them important centers and urban heritage poles to develop the tourism sector in particular and economy in general.

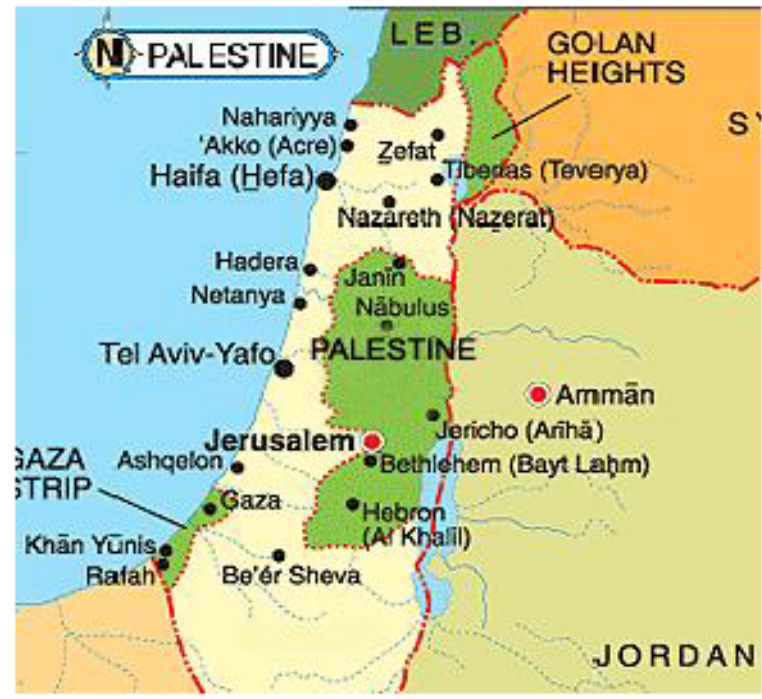

Figure 1: Map of Palestine.

This research aims to identify the aspects of strengths and weaknesses in cultural and historical potentials of urban heritage for the Palestinian cities (Hebron and Bethlehem in this case), the extent of their relation to the tourism sector, and their role in developing the tourist product. In addition, the research seeks to highlight the cultural civilization of the area through which the character of the community was formed to indicate its identity and connection with other civilizations witnessed by the area throughout history.

As for the research methodology, the study depended on historical approach to trace the history and historical heritage monuments in the two cities. Besides, analytical, descriptive, and inductive approaches were utilized with the help of maps, drawings, planning, and extensive experience in the field. The study also aims at achieving economic benefit from the civilization heritage that is considered to be a valuable treasure that needs to be invested in and maintained within the framework of tourism sustainable development.

The study concluded with presenting deductions and recommendations that aim at achieving sustainable development of the architectural heritage within a sound social environmental framework, in addition to economic and tourism sustainable development. These recommendations and suggestions can be applied to benefit achieving a comprehensive development in all Palestinian cities [1]. 


\section{Historical cities: important tributaries of cultural tourism}

\subsection{Historical cities and cultural tourism}

The tourism sector is an important component of the Palestinian economy. It is at the core of services that lies on a road network of hundreds of kilometers. In addition, there are two international airports in Jerusalem and Gaza; however, they are both closed by an Israeli military order.

There are several international cultural sites in Palestine, the main of which is Jerusalem's old city, with all its churches and mosques (like Al Aqsa Mosque, Church of the Sepulcher, Dome of the Rock, etc.). Furthermore, other sites one can see are the Church of the Nativity in Bethlehem city; the Abraham mosque and Bir Haram Al Rameh and Beit Einon in Hebron. Jericho is also rich with archeological sites and all the old cities in Jerusalem, Hebron, and Nablus are considered part of the historical sites in Palestine [2].

During the last decades, the formal tourism activities concentrated on the old cities in Palestine since the old cities show the vernacular culture as well as the traditional industries and handcrafts Palestine enjoys. The Old City of Jerusalem, for example, is considered an open living museum that contains the Aqsa mosque, Dome of the Rock, Church of the Sepulcher and a series of traditional shops and motels while Jericho - the lowest area in the world - is considered among the first cities and embraces the old houses' ruins, in addition to Hisham's Palace and the Dead Sea. To the south of Palestine lies Hebron city that is related to Prophet Ibrahim who settled there to rest. The city opens its streets, mosques and Souks (Markets) and castle for the visiting tourists.

\subsection{The role of architectural heritage in supporting tourism in the cities of Bethlehem and Hebron}

Tourism is considered a cultural phenomenon since tourists seek to know the characteristics of the area of destination from historical, cultural and environmental perspectives. Although tourists have a limited picture in most of the times, tourism creates an added value to his/her knowledge. The knowledge varies according to the amount - gained from the culture and lifestyle of the residents of the host country. Thus, many countries have cherished and revived parts of the archeological sites, museums, old cities, traditional handcrafts and cultural events in order to boost cultural tourism.

Bethlehem and Hebron are rich in their historical sites; many old buildings date back to the Phoenicians, Romans and Islamic eras. Bethlehem and Hebron are also of oldest commercial centers on the commercial road between Syria (alSham) and Egypt; moreover, the two cities have many historical sites that attract tourists from all over the world. Hence, both cities have an important role economically because of their strategic location especially Hebron that is surrounded by mountains [3]. 


\section{The city of Bethlehem}

Bethlehem city is located between the most important Palestinian cities Jerusalem and Hebron- where the city is just a few kilometers away from the south of Jerusalem and 20 kilometers to the north of Hebron. It is the 7th largest city in Palestine with an approximate population of 40.000 citizens. The city is distinguished by being the point of convergence between the east and west as well as the north and south of Palestine [4].

\subsection{Most prominent religious and tourism monuments in Bethlehem}

\subsubsection{The Church of Nativity}

It is considered as the main religious monument in Bethlehem that was ordered to be built by Empress Helen, mother of Emperor Qustantin and based on his request in $325 \mathrm{AC}$ after acknowledging the Christianity as an official religion for Roman Empire. The Church of Nativity in Bethlehem was established along with the Church of Sepulcher in Jerusalem; however, the Church of Saint Helen was destroyed in 529 by the Samaritans and was rebuilt once again after years by Emperor Justinian I to remain until our present time. From time to time, various repairs due to damage and tampering are being done (Figure 2).

\subsubsection{Mar Elias Monastery}

Located on a hill to the north of Bethlehem and built in the 6th AC century. It is said that Hercules, King of Romans, rebuilt the monastery after expelling the Persians from the area. The monastery was affected by the Palestinian-Zionist war in 1948 and 1967 due to its location on truce line. The last restoration made for the monastery was in 1976. The city of Bethlehem is also surrounded by a number of historical places, namely (Figure 3).

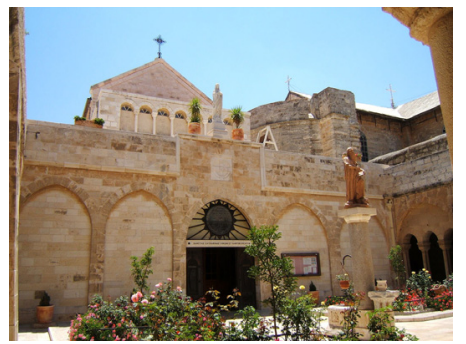

Figure 2: The Church of Nativity.

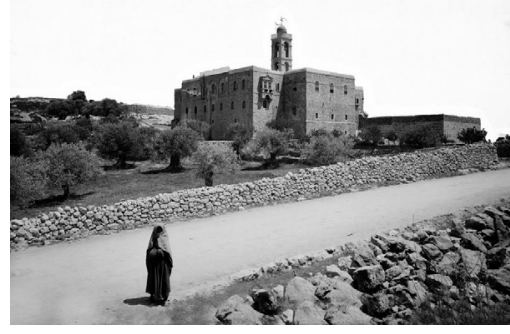

Figure 3: Mar Elias monastery.

\subsubsection{Rachel's Tomb}

Rachel is Prophet Jacob's wife and mother of Prophet Joseph. She died in this site at the entrance of Bethlehem while she was giving birth to her second son Benjamin. Rachel's tomb was built on the Islamic style of architecture and established in 1560 by an order of the Wali "governor" of Jerusalem (Figure 4). 


\subsubsection{David Wells and the Well of Qadismo}

They are old historical wells. The first is located in the city of Bethlehem, while the second is near Mar Elias monastery on the trade road between Egypt and the Levant. David drank from the first well when he invaded Bethlehem, while the second was used by Virgin Mary who drank while she was on her way from Nazareth to Bethlehem.

\subsubsection{Solomon's Pools}

Located about 4 kilometers to the south of Bethlehem and they are three pools still streaming until our current days with 50 meters that separate each from the other. Water was running from the pools to Jerusalem through canals carved in the stones and properly built.

The canal was extended at the time of Herodotus and restored at the time of Arabs' ruling. In 1918, water was running to Jerusalem through pipes. Around the pools are a number of archeological sites and old ruins including guarding castles, residential sites, tombs, and mosaic pieces (Figure 5).

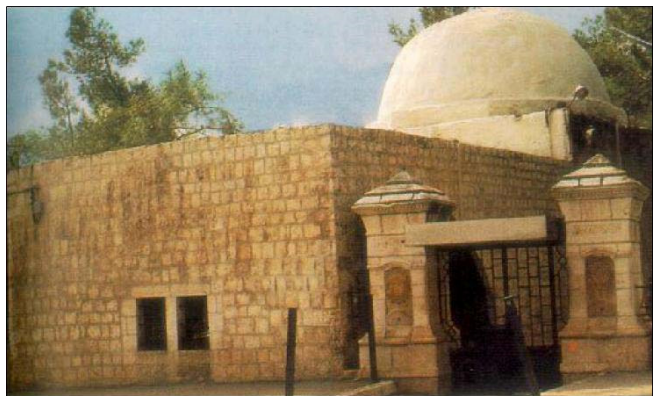

Figure 4: Rachel's Tomb.

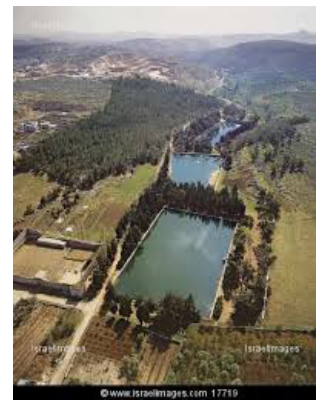

Figure 5: Solomon's pool.

\subsubsection{Tel Fredis (Herodotus)}

It is an industrial conical hill like a volcano whose diameter reaches up to 100 meters. It is located to the southeast of Bethlehem and overlooks, from far distances, al-Aghwar "the Jordan Valley", Jerusalem, and the surrounding areas.

It was established by Herodotus who also built palaces and fortified forts surrounded by a trench used to be filled with water. Behind the trench lies a round wall made of huge rocks upon which watch towers were established. In the middles centuries, Crusaders turned it into a fortress after restoration.

\section{The city of Hebron}

Hebron is one of the rare Middle Eastern cities to be continuously inhabited throughout the ages in spite of persistent attacks seeking to destroy it and chase away its population. The reason behind this continuity might be related to its sacred status on one hand; and to its strategic and fertile location on the other [5]. 


\subsection{Most prominent religious and tourism monuments In Hebron}

\subsubsection{Tal al-Rumaida}

Urban human settlement in the region can be dated back to around $1700 \mathrm{BC}$, with remnants of such presence clearly visible in Tal al-Rumaida (Ancient Hebron), which lies adjacent to the northwestern part of the Old City. There certainly are signs of an even older rural human presence (late stone Age-early Bronze Age) but archeological excavations have not reached any clear conclusions regarding that.

The other site which left an indelible mark on the city's history over centuries is al-Roma Sanctuary (also known as Mamre/Mambre), located approximately 4 kilometers to the north of the Old City, at an altitude of 991 meters. The history of al-Roma site has not been seriously explored yet, except for its sacred part, and written data concerning it reveal its religious and economic significance. An international market used to be held there on an annual basis, was considered as one of Palestine's major market places under Roman rule. The site continued to play this role until the Islamic Conquests. It seems that part of Hebron's religious and historical heritage was closely linked to it, especially during the Roman era, following the destruction of the city built on Tal al-Rumaida [6].

\subsubsection{The Ibrahimi Mosque}

The Ibrahimi Mosque in Hebron is the world's oldest sacred building still in use today in a practically continuous manner. It is believed to host the remains of God's prophet Abraham, his wife Sarah, their sons Isaac and Jacob and the latter's wives Leah and Rebecca. Most probably, the sanctity of the site has largely contributed to the cultural continuance of Hebron and made the town renowned enough over the world, to give its name to other places around the world, namely in the United Kingdom and the United States [7] (Figure 6).

\subsubsection{The Old Town}

It is very probably that, during the Islamic conquests, no buildings existed outside Tal al-Rumaida except for the enclosure surrounding the Tombs of the Patriarchs. This leads us to the conclusion that the city's present location on the edge of the Hebron valley resulted from the shift that occurred after the Conquests: thus moving closer to the Ibrahimi mosque, and eventually surrounding it from all sides. This has created the concept of a "holy city" like Mecca, Medina and Jerusalem; hence its name Khalil al-Rahman emerged (Figure 7).

\section{The sustainable development for the urban heritage and tourism sector}

Cities, landmarks and historical sites are important resources as the natural and industrial resources. The level of civilization of any country is not assessed by the number of historical sites but by the amount of awareness and the way of 


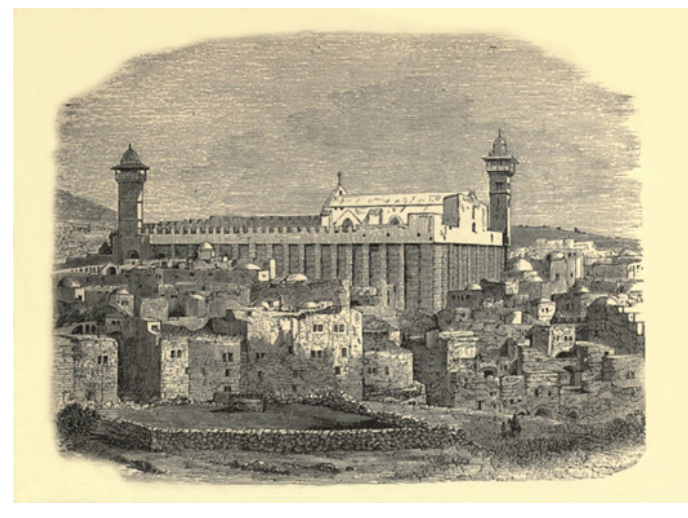

Figure 6: The Ibrahimi Mosque.

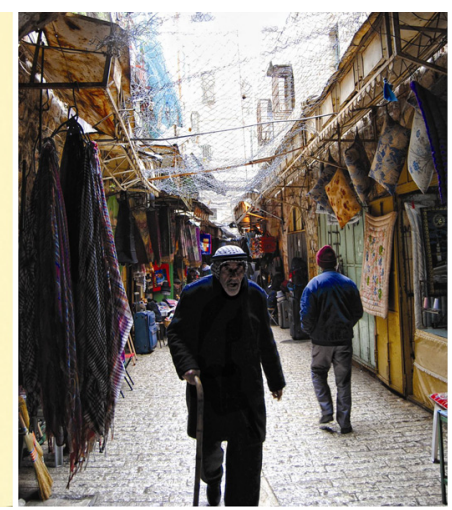

Figure 7: The Old Town.

reservation and the national use of such places. These sites should be reserved and treated as living spaces that almost talks to you telling their stories and not only a pile of stones.

Palestine, Egypt and Morocco are very rich of the human heritage. They are full of archaeological sites and historical places that varies on the architectural, artistic, cultural and economical levels.

Unfortunately, some Palestinian cities are now facing danger that threaten their historical and architectural heritage. The first is the lack of awareness towards the heritage and the development process that does not take into consideration the importance of the historical cities [8].

It is painful that the development of the old cities destroys many important treasures to turn it into commercial centers on residential buildings because of:

- a lack of awareness of the institutions;

- a lack of rules;

- having no reservations places of the old cities;

- having no standards for the development of the old city;

- a lack of resources;

- a lack of assessment procedures.

Hence, it is important to suggest a plan to reserve and manage the architectural heritage to preserve the historical cities and here we can propose a twodimensional plans:

a) Changing the concept of utilizing this important resources;

b) Finding ways of implementing projects to preserve the historical cities and to suggest policies and a framework to help the authorities to propose projects that preserve the architectural heritage and help the community to utilize this important resources.

In order to come up with these goals, we propose the following:

1. Capacity building of local experts;

2. Awareness of the local communities; 
3. To get lessons from other countries who have developed historical cities;

4. Developing rules to preserve the historical cities;

5. Adapting comprehensive policies between planning and reservation;

6. Not considering old cities as museums but also finding ways to rehabilitate the cities economically and socially.

In order to explain the development, these policies are to be adapted in both Hebron and Bethlehem:

1. Developing the infrastructure;

2. Rehabilitating the old architectural building;

3. Providing series for the tourism section;

4. Editing the urban planning rules to consider the historical sites.

\section{The architectural plan}

1. Providing infrastructure for the historical areas;

2. Rehabilitation of the old properties;

3. Providing new spaces for the tourism services;

4. Revision of the land use.

\section{The environmental plan}

1. Providing assessment criteria and EIA;

2. Environmental management plan;

3. Land use control and preserving the hand craft.

\section{Methods of preserving architectural heritage of the old cities}

It is important to preserve the architectural heritage in Bethlehem and Hebron cities since it is an un-renewable resource and the management of this heritage shows the respect of our ancestors and the attention for the new generations. Moreover, it is a source of beauty and human behavior that reflects culture and shows a visual expression of the past events; it is also a physical reflection of rational changes by time, hence, it is important to find ways to preserve this heritage by:

\subsection{Technical methods}

- Developing a guiding plan to organize the projects of rehabilitation to ensure the balance between the urban area and the local environment;

- Preparing the national register for the historical building and places;

- Ensuring better quality of the rehabilitation projects by having the capacity building of the workers and adapting modern technologies. 


\subsection{Managerial and legal methods}

- Developing a legal framework to conserve historical buildings and developing standards and rules for the construction within the borders of the historical area in both cities;

- Developing a plan to determine the responsibilities of each organization that is involved in the Protection of the architectural heritage and the way of cooperation between the organizations.

\subsection{Continuing implementation the developments plans}

It is important to ensure the sustainability of the development and to adapt any urgent change that may occur, and this can be done by having an independent organization on the architectural heritage level.

\subsubsection{Developing rules that protect the architectural style of historical areas in both cities}

\subsubsection{The sustainability of community participation}

- Increase the participation of the target group for the planning on the execution levels in both cities;

- The participation of the organizations to increase the awareness towards the architectural heritage.

In conclusion, the sustainability of participation of the local community can be insured by having financial resources and awareness campaigns and by formatting committees that is concerned with architectural heritage and the development of the tourism sector [8].

\subsection{The project of host houses as a factor to increase the value of urban heritage of the old cities}

According to the field studies, the projects of host houses play an important role in preserving architectural heritage. We found that the investment in this field has started by the Palestinian businessmen who live abroad, the success of their projects led the local investors to invest in such projects that is concerned with rehabilitating old houses in Bethlehem and Hebron, Jasser Palace in Bethlehem is a very successful example of such investments, in addition to Al-Nazer that is invested by B.C.

This project will be an added value for the two cities and other cities since such projects:

- Protecting the old buildings from deterioration;

- Creating economical thriving;

- Creating activities;

- Flourishing the handcrafts and creating jobs in the phase of construction. 


\section{The problems architectural heritage suffers from in Bethlehem and Hebron}

Although architectural heritage plays an enormous role in the economical process in general and in the tourism sector in particular, and despite its role of preserving the local identity, the architectural heritage suffers from many problems especially the urban development process that is very dynamic and contrast to the urban heritage of both cities [9].

\subsection{Resources of funding}

Palestine is one of the countries that is very rich with its urban heritage, however, the Israel occupation tries with all the ways to ruin this heritage to ruin also the Palestinian identity that is attached to it. On the other hand, several organizations tries to support this sector especially the Palestinian government that is authorized to get the fund from the gulf countries, banks, the European Union, in addition to other countries like Germany, Spain, etc.

\section{The results}

Bethlehem and Hebron cities are both famous with religious tourism, the peak is seen in the religious events periods, this reflects under evaluating these resources that should be values and utilized to ensure the sustainability of tourism all over the year.

It is important to cooperate on all the levels in order to preserve the old cities from deterioration and to start conserving and rehabilitating the old buildings, moreover we should start promoting for these sites [10].

\section{Recommendations}

The development of tourism and heritage and the link between them can be done through adopting several concepts like:

1. The participation of the local communities in the restoration and preservation and encouraging the tourism sector.

2. Developing the managerial system of the urban heritage since it is a main tool to encourage the tourism.

3. Ensuring the relationship between historical and tourism sites.

4. The cooperation of the organizations (like NGOs, the Ministry of Tourism and the Ministry of Culture) to develop a common policy to manage the urban heritage.

5. Utilizing the use of diversity of the urban heritage in the tourism sector.

6. Increasing the awareness of the local communities towards the importance of the heritage. 
Moreover, sustainable development of the architectural heritage in Bethlehem and Hebron should:

- continue historical buildings and create data base for them;

- formulate workshops for the capacity building of local professionals;

- create libraries that contains the resources of these two cities;

- $\quad$ preserve intangible heritage;

- use local materials for buildings;

- promote social equality by fulfilling our needs without compromising future generation needs from meeting their own;

- $\quad$ support handcrafts and the local industries;

- use some historical buildings for tourism development;

- create maps to illustrate the historical sites and buildings in the two cities.

\section{References}

[1] Abu Hijer Amneh Ibrahim. Encyclopedia of Palestine, Towns and Villages. Osama House for publishing and Amman - Jordan, 2003.

[2] Nakhleh, Amin. The West Bank and Gaza, American Enterprise Institute for public Policy Research, Washington, D.C., 1979.

[3] Kananeh, Sharif. A study in the Culture, and Heritage and Identity first edition, 2011.

[4] Shomali Qustandi and Sawsan. A Guide to Bethlehem and the Holy land, Bethlehem - Palestine, 1998.

[5] A group of researchers. Old Hebron, The Charm of a Historical City and Architecture Hebron Rehabilitation Committee Palestine, 2009.

[6] Abu Rmeiles, Salah Musa. The Ibrahimi Mosque. First edition, Bait AlMaqdes for publishing - Palestine, 1985.

[7] A group of researchers. Old Hebron, The Charm of a Historical City and Architecture Hebron Rehabilitation Committee Palestine, 2009.

[8] Dweik Ghassan. Revitalization of the old city of Hebron, PHD research, Bukarest, Romania, 1998.

[9] Feilden, Barnard M. Conservation of Historic Buildings Technical Studies in the Arts, Archaeology, and Architecture, 1982.

[10] Omar, Mohammed Al-Attar. The tourism industry and their economic importance first edition Journal of human studies, Dunkla, Sudan, 2010. 